\title{
Growth and Distribution of Roots of Dioscorea Alata L. Do Not Respond to Mineral Fertiliser Application
}

\author{
V.K. Hgaza ${ }^{\mathrm{a}, \mathrm{b}, \mathrm{e}}$, L.N. Diby ${ }^{\mathrm{b}, \mathrm{d}}$, T.B. Tiéd ${ }^{\mathrm{d}}$, A. Tschannen ${ }^{\mathrm{b}}$, S. Akéa, A. Assa ${ }^{\mathrm{c}}$ and E. Frossard ${ }^{\mathrm{e}, *}$ \\ ${ }^{a}$ Laboratory of Plant Physiology, UFR Biosciences, University of Cocody-Abidjan, Côte d'Ivoire \\ ${ }^{b}$ Centre Suisse de Recherches Scientifiques (CSRS), Abidjan, Côte d'Ivoire \\ ${ }^{c}$ Deceased, Department of Earth Sciences, University of Cocody-Abidjan, Côte d'Ivoire \\ ${ }^{d}$ Department of Water, Forest and Environment, National Institute of Technology FHB, Yamoussoukro, Côte d'Ivoire \\ ${ }^{e}$ Swiss Federal Institute of Technology (ETH Zurich), Institute of Agricultural Sciences, Eschikon 33, CH-8315 Lindau, \\ Switzerland
}

\begin{abstract}
Water yam (Dioscorea alata) is a staple crop for many of the poorest in the tropics. Yam tuber response to fertiliser application has been reported to be erratic. We hypothesised that this variable response could be due to the development of a suboptimal root system that would not allow the plant to capture the nutrients added with the fertiliser. To verify this hypothesis we studied during two seasons (2006 and 2007) in Central Côte d'Ivoire, the growth of yam root system in relation to plant growth as affected by fertiliser input, using sequential root coring. In addition, we assessed the horizontal and vertical distribution of yam roots using the wall profile method in the same site. Three root types (seminal, adventitious and tubercular roots) were identified. Roots grew within the mound until 100 days after planting (DAP) and afterwards, extended radially in the soil outside of the mound remaining in the first soil horizon (15 cm depth). Maximum root extension was observed at 160 DAP. Root length density and root mass density were higher at higher soil temperature whereas the average root diameter decreased at higher soil temperature. Specific root length did not change with soil temperature. Root growth parameters were not affected by fertiliser application. Roots were mostly distributed in clumps. As tuber yield formation was independent from root growth we conclude that the root system of this cultivar did not limit tuber productivity. Other factors have to be considered to explain the variable response of yam to mineral fertiliser additions.
\end{abstract}

Keywords: D. alata, root system, soil core technique, wall profile method, root growth parameters, root distribution pattern.

\section{INTRODUCTION}

Yam (Dioscorea spp) is a tuber crop which plays an important role for food security in West Africa. Among the dozen or so of cultivated yam species, the main species grown in West Africa are Dioscorea rotundata Poir., Dioscorea cayenensis Lam. and Dioscorea alata L. Yam is demanding in terms of soil fertility, and it is generally the first crop after long term fallows in traditional cropping systems [1]. However, soil fertility is declining in many yam producing areas of West Africa due to shortening fallow duration, nutrient mining, and lack of adapted agricultural practices to restore soil fertility [2]. Several attempts have been undertaken to overcome this challenge with mineral fertiliser application, but tuber yield response of yams has been erratic [1,3-5]. This irregular response might be related to a suboptimal distribution of roots, which would not allow an efficient uptake of added nutrients.

*Address correspondence to this author at the Emmanuel Frossard, Swiss Federal Institute of Technology (ETH Zurich), Institute of Agricultural Sciences, Eschikon 33, CH-8315 Lindau, Switzerland; Tel: +41 5235491 40; Fax: +41 5235491 19; E-mail: emmanuel.frossard@ipw.agrl.ethz.ch
Testing the relation between the root morphology of yam and its response to mineral fertiliser application is challenging because of our limited knowledge on the yam root system. The yam's root system has been described [6-8] but not yet linked to the fertiliser response of the crop. Furthermore, root distribution patterns may also be affected by the study technique used $[9,10]$.

Two cultivars representing the major species, D.rotundata and D. alata were used in an extensive field trial in Côte d'Ivoire in 2006 and 2007 to investigate root growth and distribution in relation to yam growth and tuber yield. Only the results pertaining to D. alata are presented here. Root growth was studied in yams growing in the absence or in the presence of a mineral fertiliser by analysing the variations of the root length density, the root mass density, the specific root length, and of the average root diameter over the two growing seasons using sequential soil coring. In addition, we assessed in 2006 and 2007, the horizontal and vertical distribution of yam roots using the wall profile method at the same site at two points in time, on yams that had received mineral fertiliser applications. 


\section{MATERIALS AND METHODS}

\section{Site and Soil Preparation}

A series of two experiments were repeated in 2006 and 2007 at the field station of the Centre Suisse de Recherches Scientifiques en Côte d'Ivoire based in Bringakro (Côte d'Ivoire), about $180 \mathrm{~km}$ north-west of Abidjan. The station is located in a transitional equatorial climate zone at the interface between a moist semi-deciduous forest and a shrub savannah. Rainfall distribution in the region is characterised by a bimodal distribution pattern with two rainy seasons from March to June and from September to October. Between them, there is a short dry season (July to August) and the long dry season period is from November to February. The experiments were installed at a savannah site ( $\mathrm{N}^{\circ} 40^{\prime}$, W $\left.5^{\circ} 09^{\prime}\right)$ where the selected plot was cleared from vegetation and mounds of ca. $50 \mathrm{~cm}$ height were manually prepared with hoes at a density of 1 mound $\mathrm{m}^{-2}$. Field preparation was identical for both experiments described below. Both experiments were conducted on the same plot respectively in 2006 and 2007.

\section{Planting Material and Cultural Techniques}

An improved cultivar of the species $D$. alata, TDa 95/00010, introduced at the Centre Suisse de Recherches Scientifiques en Côte d'Ivoire in 1998 by the International Institute of Tropical Agriculture (IITA, Ibadan, Nigeria) was used. Tubers were cut into small pieces known as "sett" weighing $100 \mathrm{~g}$ each. Due to the existence of a positive sprouting gradient from the tail to the head of yam tubers [11], only the heads part of the tubers were used as planting materials to ensure homogeneous germination in all treatments. The setts were soaked in a watery mixture of $600 \mathrm{~g}$ diazinon $\mathrm{L}^{-1}$ (insecticide), 240g oxamyl L $\mathrm{L}^{-1}$ (nematicide) and mancozebe $80 \%$ (fungicide) and air-dried for a day before planting (IITA, pers. com). One sett was planted per mound. During the growth cycle, plots were weeded monthly. In 2007, the soil was treated against nematodes using $240 \mathrm{~g}$ oxamyl L $\mathrm{L}^{-1} \mathrm{ha}^{-1}$ two weeks before planting. The yam growing period extended from May to December which included the short dry season (July to August) and the beginning of the long dry season (November and December). Plants were irrigated during water shortage periods to avoid water stress.

\section{Experimental Design of the Field Experiments}

The first field experiment served to assess root length density, root mass density, specific root length, and average root diameter in relation to plant production in the presence or absence of a fertiliser input, while the second aimed at mapping the vertical and horizontal distribution of roots.

The first field experiment was arranged in a randomised complete block design with two factors (yam species $D$. alata and $D$. rotundata, and fertiliser input or not) and four replicates in plots measuring $9 \mathrm{~m} \times 4 \mathrm{~m}$ each i.e. 36 plants per plot. A rate of $160-180-10-110 \mathrm{~kg} \mathrm{ha}^{-1}$ of N-K-P-Ca, respectively, added in the form of $\mathrm{NO}_{3} \mathrm{NH}_{4}, \mathrm{~K}_{2} \mathrm{SO}_{4}$ and $\mathrm{Ca}\left(\mathrm{H}_{2} \mathrm{PO}_{4}\right)_{2}$ was compared to a control where no fertiliser was applied. The second field experiment was a randomised complete block design with one factor (yam species: $D$. alata, and D. rotundata) and four replications in plot measuring $5 \mathrm{~m} \mathrm{x} 4 \mathrm{~m}$ each i.e. 20 plants per plot. All plots were fertilised in this experiment. In both experiments, the fertiliser was applied in two equal splits by broadcasting at the maximum growth of the aboveground organs and during tuber bulking corresponding to 90 and 130 DAP, respectively.

\section{DATA COLLECTION}

\section{Soil Characteristics and Climate Data}

Soil samples were randomly sampled in the first $20 \mathrm{~cm}$ layer of the plot before installing the experiments in 2006 . Soil texture was determined by sedimentation, and the total $\mathrm{C}$ and total $\mathrm{N}$ were measured with the Walkley and Black [12] and Kjeldahl methods [13], respectively. The $\mathrm{pH}$ was measured in a 1/2.5 soil/water ratio. Rainfall and soil temperature at $0-20 \mathrm{~cm}$ depth were measured in both growing seasons using an automated weather station (http://www. delta-t.co.uk) installed on the experimental site.

\section{Root Growth Parameters Measurement}

In the first experiment, soil cores were sequentially sampled with a root auger by Eijkelkamp (http://www.eijkelkamp.com) measuring $15 \mathrm{~cm}$ in length and $754 \mathrm{~cm}^{3}$ in volume. Samples were collected during the vegetative growth phase (75 DAP), at tuber initiation (100 DAP), during the tuber growth phase (130 and $160 \mathrm{DAP})$ and during the tuber maturation phase (190 DAP). At each sampling date, soil cores were collected on two adjacent mounds per plot and on four sides of each mound (Fig. 1). Soil cores were first sampled in the $0-15 \mathrm{~cm}$ horizon $\left(\mathrm{H}_{1}\right)$ and in the $15-30 \mathrm{~cm}$ horizon $\left(\mathrm{H}_{2}\right)$ at a distance of $25 \mathrm{~cm}$ from the top of the mound where the plant emerged, and then sampled at a distance of $50 \mathrm{~cm}$ from the top of the mound in the $0-15 \mathrm{~cm}$ horizon $\left(\mathrm{H}_{3}\right)$ and in the 15-30 cm horizon $\left(\mathrm{H}_{4}\right)$. After each sampling, soil cores were transported to the laboratory where yam roots were separated from soil by elutriation in water [14]. Afterwards, the roots were gently rinsed with water and then carefully spread out in a thin layer of water $(2-3 \mathrm{~mm})$ on a transparent tray for scanning with the WinRhizo v. 2003b software package (http://www.regent.qc.ca) as described by Himmelbauer et al. [15] to measure the total root length and the average root diameter (ARD, mm). Subsequently, roots were removed from the tray and dried at $70^{\circ} \mathrm{C}$ for $72 \mathrm{~h}$. The root length density (RLD, $\mathrm{cm} \mathrm{cm}^{-3}$ ) was estimated as the total root length per unit of soil volume, while the root mass density (RMD, $\mathrm{m} \mathrm{cm}^{-3}$ ) was the root dry biomass per unit of soil volume. The specific root length (SRL, $\mathrm{cm} \mathrm{mg}^{-1}$ ) was defined as the root length per unit of root dry weight.

After having sampled the soil cores, plants were removed to measure the total shoot (vines and leaves) biomass and the tuber and the entire root system were excavated to measure tuber and root total biomass. Plant materials were dried at $70^{\circ} \mathrm{C}$ for $72 \mathrm{~h}$ to assess their dry matter content.

\section{Root System Mapping}

In the second experiment, we drew root maps during the vegetative growth phase at 70 DAP and during the maximum root growth period (150 DAP). The root system of plants was mapped in a horizontal and a vertical profile using the trench profile method $[16,17]$. The method consists of drawing root impacts found on horizontal and vertical soil trenches on transparent sheets. Two plants per plot were destructively sampled to map the root system. One plant was 


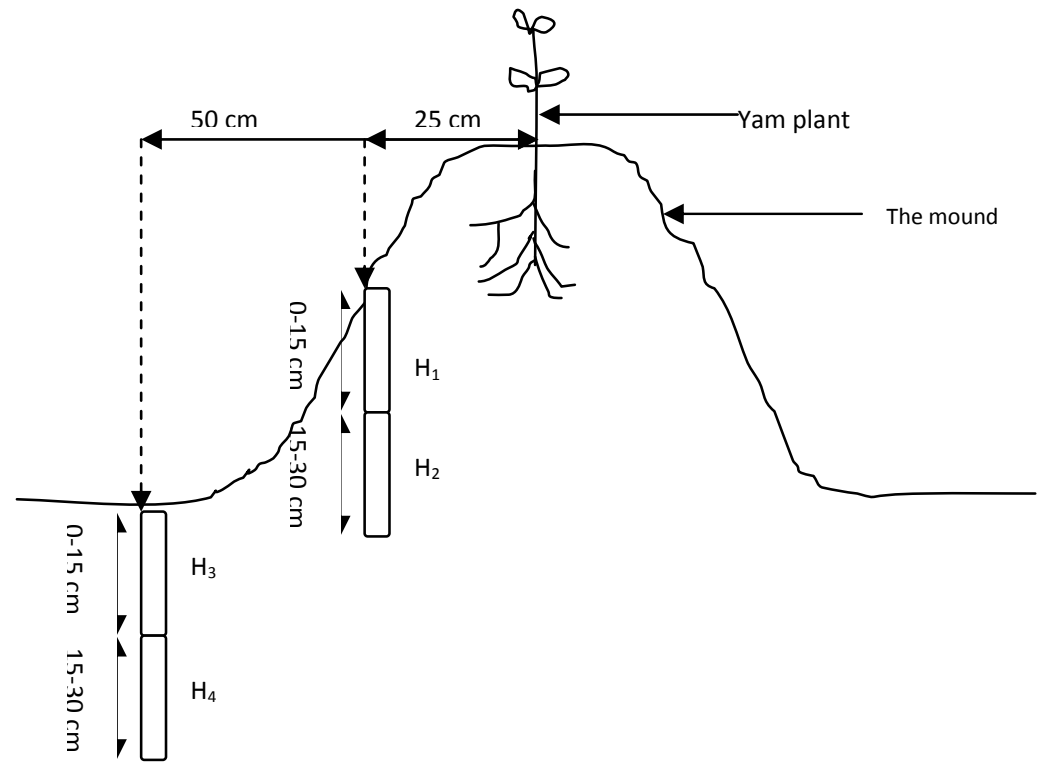

Fig. (1). Location of yam root sampling positions for the measurement of the root length density, root mass density, average root diameter and specific root length. Samples were taken on the four sides of the mound. Here, we only show one sampling side for the sake of simplicity.

sampled to map root impacts in vertical profiles located at $0 \mathrm{~cm}\left(\mathrm{~V}_{1}\right), 25 \mathrm{~cm}\left(\mathrm{~V}_{2}\right)$ and $50 \mathrm{~cm}\left(\mathrm{~V}_{3}\right)$ from the centre of the emerged plant (Fig. 2A). The other plant was used to map root impacts on horizontal profiles located at $5 \mathrm{~cm}\left(\mathrm{D}_{1}\right)$, $30 \mathrm{~cm}\left(\mathrm{D}_{2}\right)$ and $55 \mathrm{~cm}\left(\mathrm{D}_{3}\right)$ depth below the primary nodal complex (PNC) from which originate the adventitious roots (Fig, 2B). The root impacts were marked on the sheet by considering the centre of the mound as the reference point $(0,0)$. The positive $\mathrm{Y}$-axis indicated the geographic north on the horizontal maps, while the negative $\mathrm{Y}$-axis represented the depth on the vertical maps. When all the roots impacts had been reported on the plastic sheets, they were brought to the laboratory and photographed. The photos were digitalised using the scion image software (http://www.scioncorp.com) to determine the coordinates $(\mathrm{X}, \mathrm{Y})$ of the different root impacts.

\section{STATISTICAL ANALYSIS}

Analysis of variance (ANOVA) (SAS v. 9.1, SAS Institute) was used to test the effect of fertiliser application and the growing season on shoot (leaves + vines), roots and tubers dry matter production (DM) respectively, at each of the sampling date. ANOVA was also used to analyse the effect of fertiliser application, the sampling position $\left(\mathrm{H}_{1}, \mathrm{H}_{2}, \mathrm{H}_{3}\right.$ and $\left.\mathrm{H}_{4}\right)$ and the growing season on the RLD, RMD, ARD and SRL. Least significant difference (LSD) at $\mathrm{P}<0.05$ were used to distinguish significantly different means.

Regression equations were performed using SAS v. 9.1.

The nearest neighbour technique was used at $\mathrm{P} \leq 0.001$ to test the pattern of root spatial dispersion on both vertical and horizontal profile maps. This technique allows testing the distribution of data points, i.e. expected mean distance $\left(r_{E}\right)$ between roots against a Complete Spatial Randomness (CSR) distribution. The null hypothesis of CSR assumes that data points are distributed randomly, which often displays features that look like clumping [18]. The nearest neighbour index value $(R)$ is the ratio between $r_{A}$ and $r_{E}$ in the study

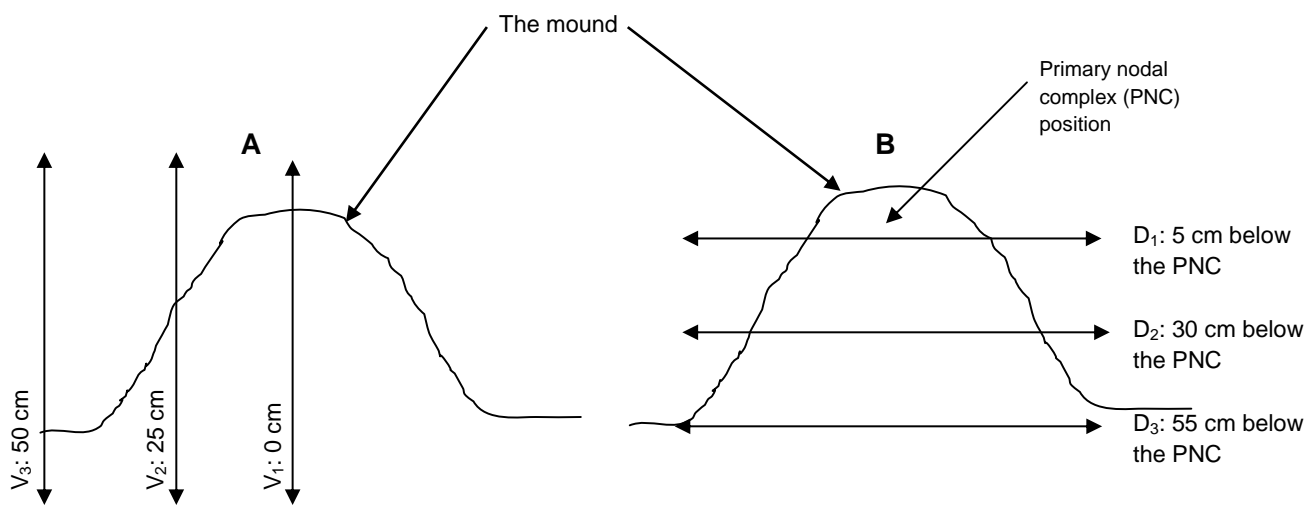

Fig. (2). Location of root mapping positions at $\mathrm{V}_{1}(0 \mathrm{~cm}), \mathrm{V}_{2}(25 \mathrm{~cm})$ and $\mathrm{V}_{3}(50 \mathrm{~cm})$ from the centre of the mound on vertical profile $($ A) and at $\mathrm{D}_{1}(5 \mathrm{~cm}), \mathrm{D}_{2}(30 \mathrm{~cm})$ and $\mathrm{D}_{3}(55 \mathrm{~cm})$ below the primary nodal complex on horizontal profile $(\mathbf{B})$. 
area, where $r_{A}$ is the mean nearest neighbour distance which is defined as the closest distance between two data points. The nearest neighbour index values range from 0 for perfectly clumped points, to $\mathrm{R}=1$ for randomly distributed points to a maximum value of $\mathrm{R}=2.15$ for uniformly distributed points [18]. The nearest neighbour analysis was performed using Surfer 8.0 software (Golden, CO, USA). The root maps were characterised by the of root impacts number (RIN), the nearest neighbour distance $\left(\mathrm{r}_{\mathrm{A}}\right)$, and the root distribution pattern derived from $\mathrm{R}$. Due to the nature of the root impacts data, no mean value was calculated per plot but data were presented for each mound.

\section{RESULTS}

\section{Soil Characteristics, Soil Temperature and Rainfall}

The clay, fine silt and coarse silt content in the first 20 $\mathrm{cm}$ soil layer were 301 (standard error $(\mathrm{SE}) \pm 31) \mathrm{g} \mathrm{kg}^{-1}, 338$ $(\mathrm{SE} \pm 42) \mathrm{g} \mathrm{kg}^{-1}$ and $362(\mathrm{SE} \pm 25) \mathrm{g} \mathrm{kg}^{-1}$, respectively. The $\mathrm{pH}_{\text {water }}$ was $5.2(\mathrm{SE} \pm 0.2)$ while the respective $\mathrm{C}$ and $\mathrm{N}$ contents were $5.7(\mathrm{SE} \pm 0.2)$ and $0.7(\mathrm{SE} \pm 0.07) \mathrm{g} \mathrm{kg}^{-1}$, respectively. Soil temperature during the growing seasons (May to
December) varied from 28 to $31^{\circ} \mathrm{C}$ in 2006 and from 24 to $26^{\circ} \mathrm{C}$ in 2007, during the growing season (Table 1).

In 2006, during the short dry season (July - August) and at the end of the short raining season (October), $420 \mathrm{~mm}$ of water was supplied to plants by irrigation (Table 1). In 2007, rainfall was high and well distributed over the growing season so that irrigation was not necessary. However, the total water received by plants in $2006(1170 \mathrm{~mm})$ was higher than in 2007 (1010 $\mathrm{mm})$.

\section{Biomass Production}

Incidences of weeds, pests or diseases were low in 2006 and 2007. The maximum shoot biomass was measured at 160 DAP in both years, while the maximum root biomass was measured at 160 and at 130 DAP in 2006 and 2007, respectively (Table 2 ). The maximum shoot and root biomass was significantly higher in 2006 compared with 2007 irrespective of fertiliser application. At the maximum shoot and root growth period, shoot biomass was significantly increased by fertiliser application in both years, while the root biomass was not affected. The applied fertiliser significantly increased tuber production in 2007 but not in 2006 (Table 2).

Table 1. Monthly Mean Soil Temperature, Recorded Rainfall and Irrigation Water (in Brackets) During the Growth Seasons of 2006 and 2007

\begin{tabular}{|c|c|c|c|c|c|}
\hline \multirow[b]{2}{*}{ Month } & \multirow[t]{2}{*}{ DAP } & \multicolumn{2}{|c|}{ Soil Temperature $\left[{ }^{\circ} \mathbf{C}\right]$} & \multicolumn{2}{|c|}{ Total water $[\mathrm{mm}]$} \\
\hline & & 2006 & 2007 & 2006 & 2007 \\
\hline May & 0 & 31 & 26 & 142 & 90 \\
\hline June & 30 & 30 & 25 & 189 & 167 \\
\hline July & 60 & 30 & 24 & $60(130) \dagger$ & 177 \\
\hline August & 90 & 29 & 24 & $41(230) \dagger$ & 140 \\
\hline September & 120 & 28 & 25 & 183 & 195 \\
\hline October & 150 & 29 & 24 & $108(60) \dagger$ & 165 \\
\hline November & 180 & 29 & 25 & 22 & 78 \\
\hline Total & & & & 1170 & 1010 \\
\hline
\end{tabular}

$\dagger$ Amount of water added by irrigation to supplement rainfall shortage in 2006 .

Table 2. Effect of Fertilisation and Year on Shoot (Leaves + Vines), Root and Tuber Dry Matter Production

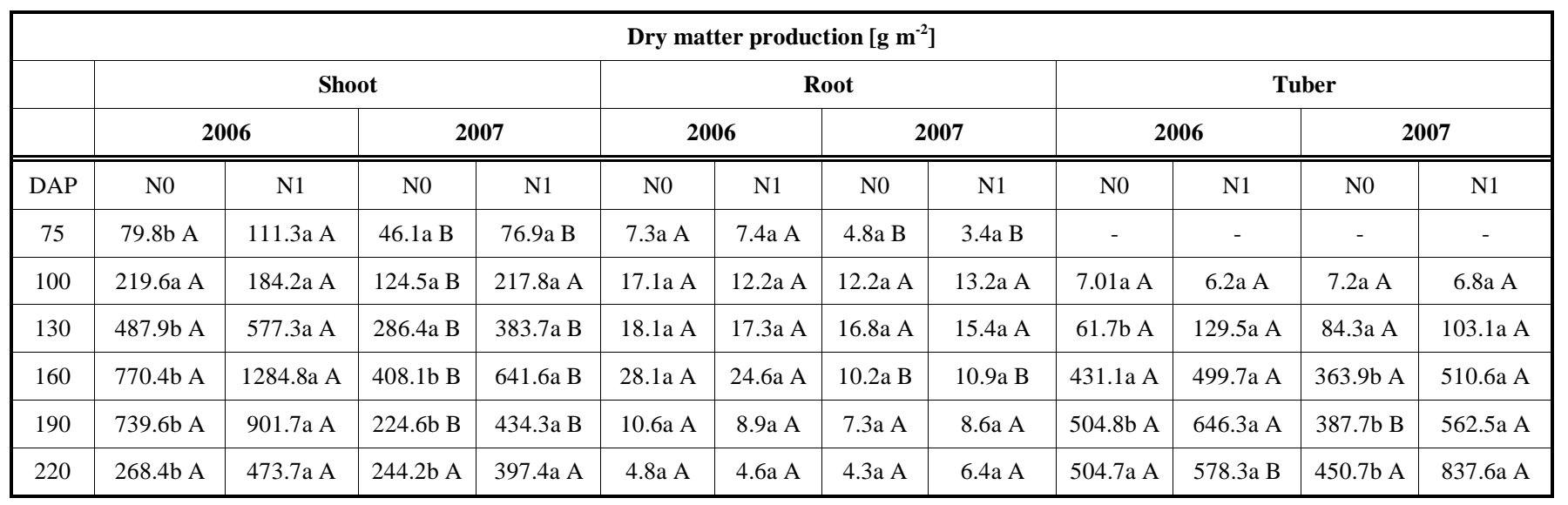

For each organ, means with the same letter in the same line are not significantly different at $\mathrm{P}<0.05$. Small letter represents comparison between non fertilised treatment (N0) and fertilised treatment (N1) in each year. Capital letter represents comparison between years for each fertilisation level. 
Indeed, in 2006, the tuber biomass of the fertilised treatment decreased between 190 and 220 DAP reaching the level of the tuber biomass of the non-fertilised treatment.

\section{Root Growth Parameters}

Three types of roots were observed: seminal roots, adventitious roots and tubercular roots. These roots derived from the planted setts, the primary nodal complex (PNC) and the newly developed tuber, respectively. However, as we could not distinguish the different root types in the soil cores, all roots were considered to estimate root growth parameters. No roots were observed below $15 \mathrm{~cm}$ (in $\mathrm{H}_{4}$ ). Mineral fertiliser inputs had no significant impact on any of the root variables measured in both years. Therefore, results present here refer to the mean values of fertilised and not fertilised plants.

The Root Length Density (RLD) did not vary significantly between mound $\left(\mathrm{H}_{1}, \mathrm{H}_{2}\right)$ and interrow $\left(\mathrm{H}_{3}\right)$ before tuber initiation $(0-100$ DAP $)$ in both years. Thereafter, RLD was significantly higher in the upper mound $\left(\mathrm{H}_{1}\right)$ and after 130 DAP, the RLD was significantly lower in the lower mound $\left(\mathrm{H}_{2}\right)$ than in the interrow space $\left(\mathrm{H}_{3}\right)$ in 2006 , but no difference was observed in 2007 (Fig. 3A). At all growth stages, the RLD was significantly higher in 2006 than in 2007. Indeed in the upper mound $\left(\mathrm{H}_{1}\right)$, the maximum RLD value was $0.62 \mathrm{~cm} \mathrm{~cm}^{-3}$ in 2006 compared with $0.37 \mathrm{~cm} \mathrm{~cm}^{-3}$
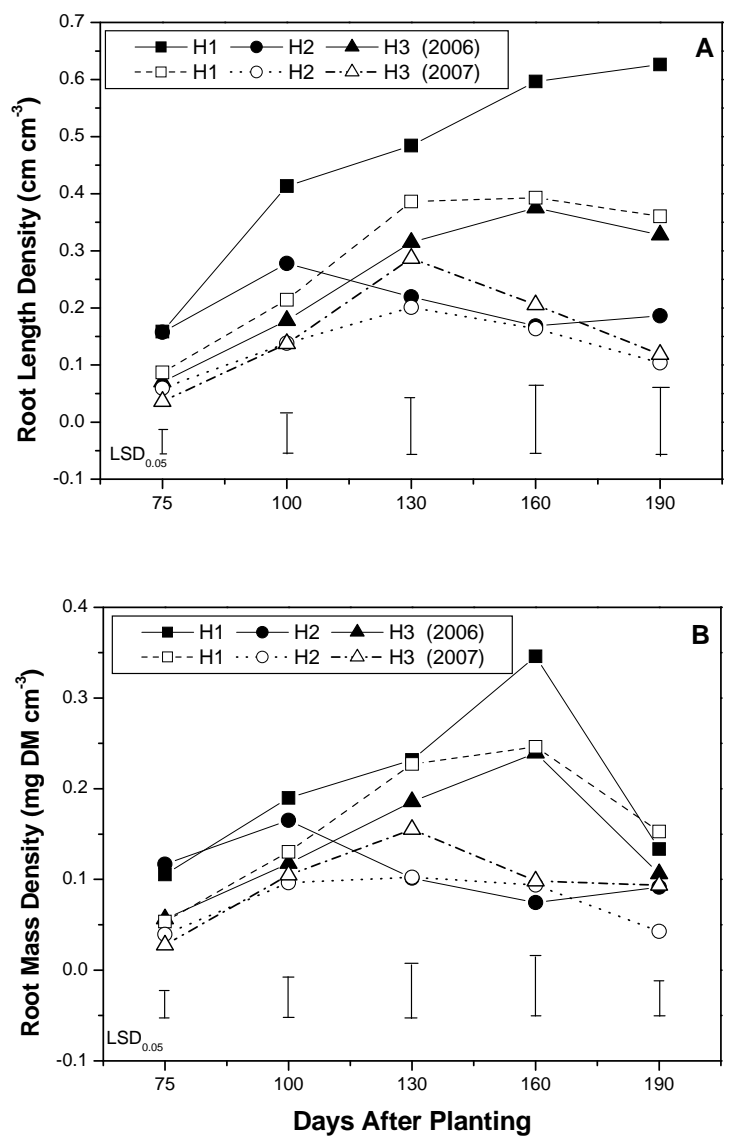

Fig. (3). Root length density (A) and root mass density (B) as affected by the year and sampling position over time with $D$. alata. Bars are t-tests $\left(\mathrm{LSD}_{0.05}\right)$ for root length density and root mass density. $\mathrm{H}_{1}, \mathrm{H}_{2}$ and $\mathrm{H}_{3}$ represent sampling position. in 2007. In the lower mound $\left(\mathrm{H}_{2}\right)$, the maximum RLD was $0.28 \mathrm{~cm} \mathrm{~cm}^{-3}$ and $0.19 \mathrm{~cm} \mathrm{~cm}^{-3}$ in 2006 and 2007, respectively. In the flat area $\left(\mathrm{H}_{3}\right)$, the maximum RLD value in 2006 $\left(0.35 \mathrm{~cm} \mathrm{~cm}^{-3}\right)$ was almost twice of that observed in 2007 $\left(0.19 \mathrm{~cm} \mathrm{~cm}^{-3}\right)$.

In both years, the Root Mass Density (RMD) was similar between $\mathrm{H}_{1}, \mathrm{H}_{2}$ and $\mathrm{H}_{3}$ prior to tuber initiation $(0-100$ DAP). Afterwards, the RMD in $\mathrm{H}_{2}$ declined drastically compared with $\mathrm{H}_{1}$ and $\mathrm{H}_{3}$ in 2006. In 2007, the RMD in $\mathrm{H}_{2}$ and $\mathrm{H}_{3}$ increased slightly between 100 and 130 DAP and declined thereafter, while the RMD in $\mathrm{H}_{1}$ increased up to a maximum at 160 DAP before declining (Fig. 3B). The root mass density was significantly higher in 2006 than in 2007 for $\mathrm{H}_{1}$ and $\mathrm{H}_{3}$ but no difference was observed between years for $\mathrm{H}_{2}$. At the maximum root growth observed at 160 DAP, the RMD in $\mathrm{H}_{1}$ was $0.33 \mathrm{mg} \mathrm{cm}^{-3}$ in 2006 compared with $0.22 \mathrm{mg} \mathrm{cm}^{-3}$ in 2007. In $\mathrm{H}_{3}$, the RMD was $0.22 \mathrm{mg} \mathrm{cm}^{-3}$ in 2006 and $0.09 \mathrm{mg} \mathrm{cm}^{-3}$ in 2007.

The Average Root Diameter (ARD) pattern over time was different between years (Fig. 4A). In 2006, the ARD declined between 75 and 100 DAP, increased slightly from 100 to 130 DAP and declined again until harvest. In contrast, in 2007 ARD declined between 75 and 130 DAP and then increased until harvest. No significant difference was observed between sampling positions in each year. The average root diameter was significantly higher in 2007 than in 2006
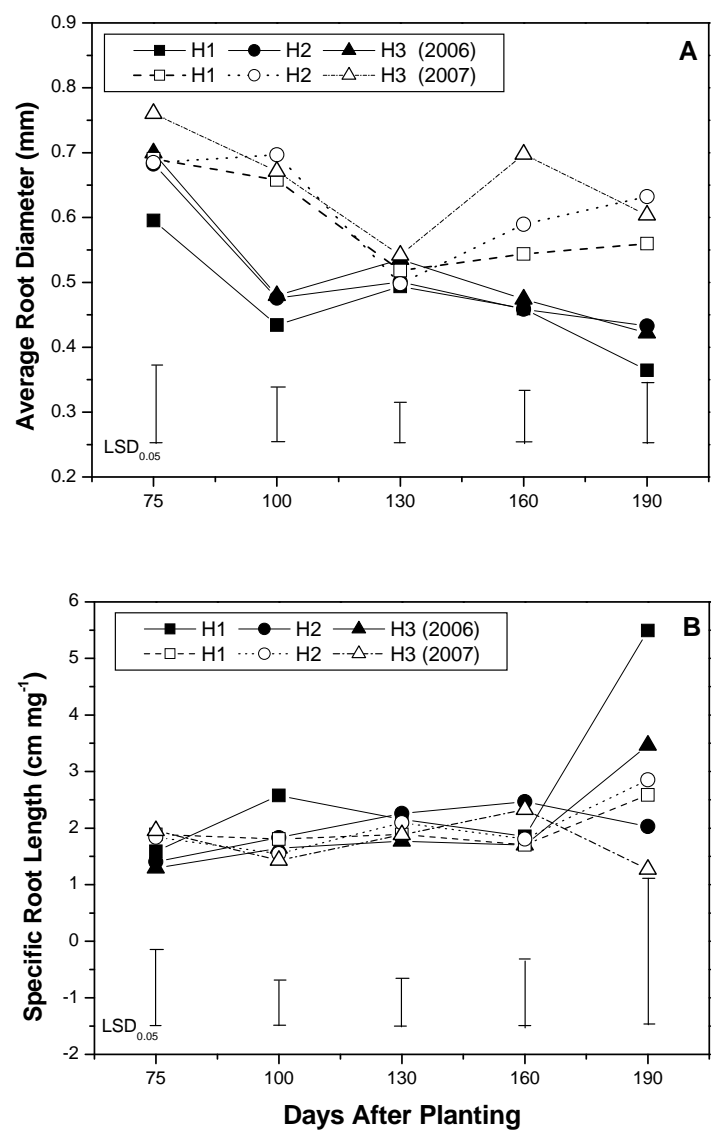

Fig. (4). Average root diameter (A) and specific root length (B) as affected by the year and sampling position over time with $D$. alata. Bars are t-tests $\left(\mathrm{LSD}_{0.05}\right)$ for average root diameter and specific root length. $\mathrm{H}_{1}, \mathrm{H}_{2}$ and $\mathrm{H}_{3}$ represent sampling position. 
at 100, 160 and 190 DAP. At 100 DAP the ARD was 0.45 $\mathrm{mm}$ in 2006 compared with $0.7 \mathrm{~mm}$ in 2007 . At the end of the growing season, the ARD was $0.45 \mathrm{~mm}$ and $0.65 \mathrm{~mm}$ in 2006 and 2007, respectively.

The Specific Root Length (SLR) was neither significantly different between years, nor between the sampling positions during the entire growing season. The specific root length was constant over time up to 160 DAP with a mean value of about $2 \mathrm{~cm} \mathrm{mg}^{-1}$ (Fig. 4B).

\section{Relationship Between Root Density and Root Impacts Number}

Means and standard deviations for both RLD (Root Length Density) and RMD (Root Mass Density) were highly correlated at sampling position $\mathrm{H}_{1}$ and $\mathrm{H}_{3}$ but not at $\mathrm{H}_{2}$ (Table 3). The coefficient of variation was high in $\mathrm{H}_{1}(54$ and $61 \%$ for RLD and RMD, respectively) and increased slightly in $\mathrm{H}_{3}$ (67\% in both cases). When combining all sampling positions (Fig. 5), the coefficients of correlation between root density and standard deviation remained high with high coefficients of variation (60-63\%).

The root impact numbers (RIN) measured in this study ranged from 0.01 to $0.17 \mathrm{~cm}^{-2}$ (Fig. 6). Root densities were highly correlated $\left(r^{2} \geq 0.80, n=8\right)$ with root impacts number (Fig. 6). The slope of the resulting equations varied from 2.2 to 3.3 for RMD and RLD, respectively, the intercept of the respective models (0.03), however, was similar.

\section{Root Mapping}

The characteristics of the maps observed on both horizontal and vertical profiles are summarized in Table 4. In both years and for each investigated plant, the root distribution patterns observed at 70 DAP evolved from random or uniform at $D_{1}$ to clump with depth $\left(D_{2}\right.$ and $\left.D_{3}\right)$ on the horizontal profile. Conversely, on the vertical profile, the root distribution pattern evolved from clump inside the mound $\left(\mathrm{V}_{1}\right.$ and $\left.\mathrm{V}_{2}\right)$ to uniform in the interrow $\left(\mathrm{V}_{3}\right)$. At 150 DAP roots were mostly distributed as clump on both vertical and horizontal profiles.

A year effect was observed on root distribution patterns in the interrow $\left(\mathrm{V}_{3}\right)$. While the roots were mostly distributed as uniform ( 2 of 3 cases) and random ( 2 of 3 cases) at 70 and 150 DAP, respectively, in 2007, they were mostly distributed as clump at both 70 and 150 DAP in 2006.

\section{DISCUSSION}

Both the soil coring method and the root mapping method give results that are often difficult to interpret. An

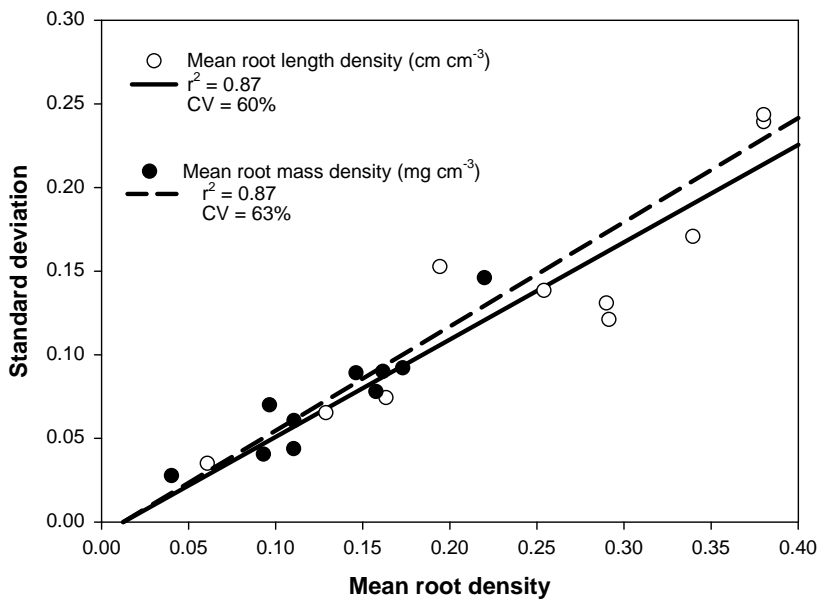

Fig. (5). Mean root (length and mass) density vs. standard deviation combining all years, treatments sampling dates and positions.

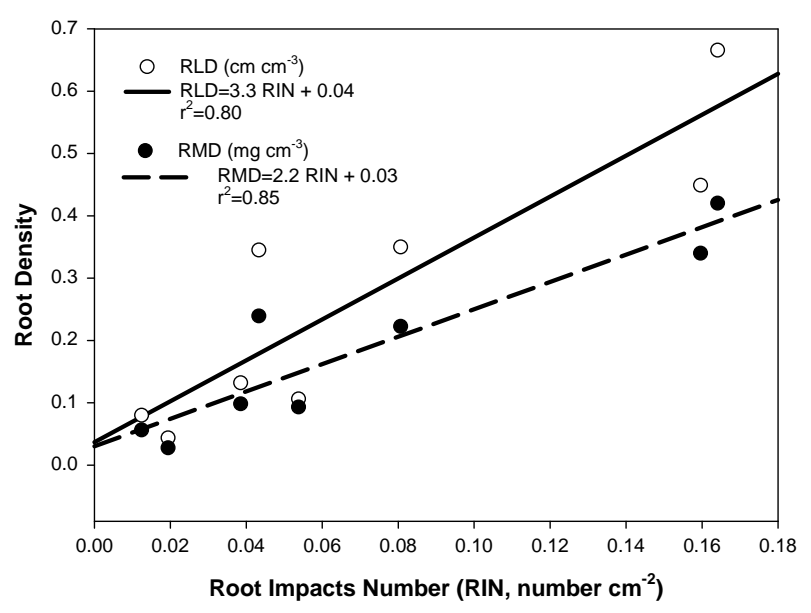

Fig. (6). Relationship between root density and root impacts number combining all years and treatments. Both root density and root impacts number have been measured at 25 and $50 \mathrm{~cm}$ from the yam plant after 70 and 150 days after planting.

unknown fraction of fine roots may be lost through the sieve in the soil coring method, while an unknown fraction of fine roots might not be taken into account by mapping the soil profile [19]. However, the significant correlations observed

Table 3. Correlation Between the Mean Root Density and the Standard Deviation at each Sampling Positions $\left(\mathrm{H}_{1}, \mathrm{H}_{2}\right.$ and $\left.\mathrm{H}_{3}\right)$ Combining All Years, Treatments and Sampling Dates

\begin{tabular}{|c|c|c|c|c|}
\hline & \multicolumn{2}{|c|}{ MRLD vs. Std dev } & \multicolumn{2}{c|}{ MRMD vs. Std dev } \\
\hline Sampling Position & $\mathbf{r}^{2}$ & $\mathbf{C V}(\boldsymbol{\%})$ & $\mathbf{r}^{2}$ & 0.82 \\
\hline $\mathrm{H}_{1}$ & 0.83 & 54 & 0.5 & 61 \\
\hline \hline $\mathrm{H}_{2}$ & 0.05 & 52 & 0.87 & 65 \\
\hline $\mathrm{H}_{3}$ & 0.88 & 67 & $\%$ \\
\hline
\end{tabular}

MRLD=Mean Root Length Density; MRMD=Mean Root Mass Density; Std dev= Standard deviation. $\mathrm{R}^{2}=$ coefficient of correlation; $\mathrm{CV}=$ coefficient of variation. 
Table 4. Root Map Patterns Observed at Different Depths (D, Horizontal Maps) and Distances (V, Vertical Maps) at 70 and 150 DAP in 2006 and 2007 using the Nearest Neighbour Test for the Null Hypothesis $\left(\mathrm{H}_{0}\right)$ of Complete Spatial Randomness

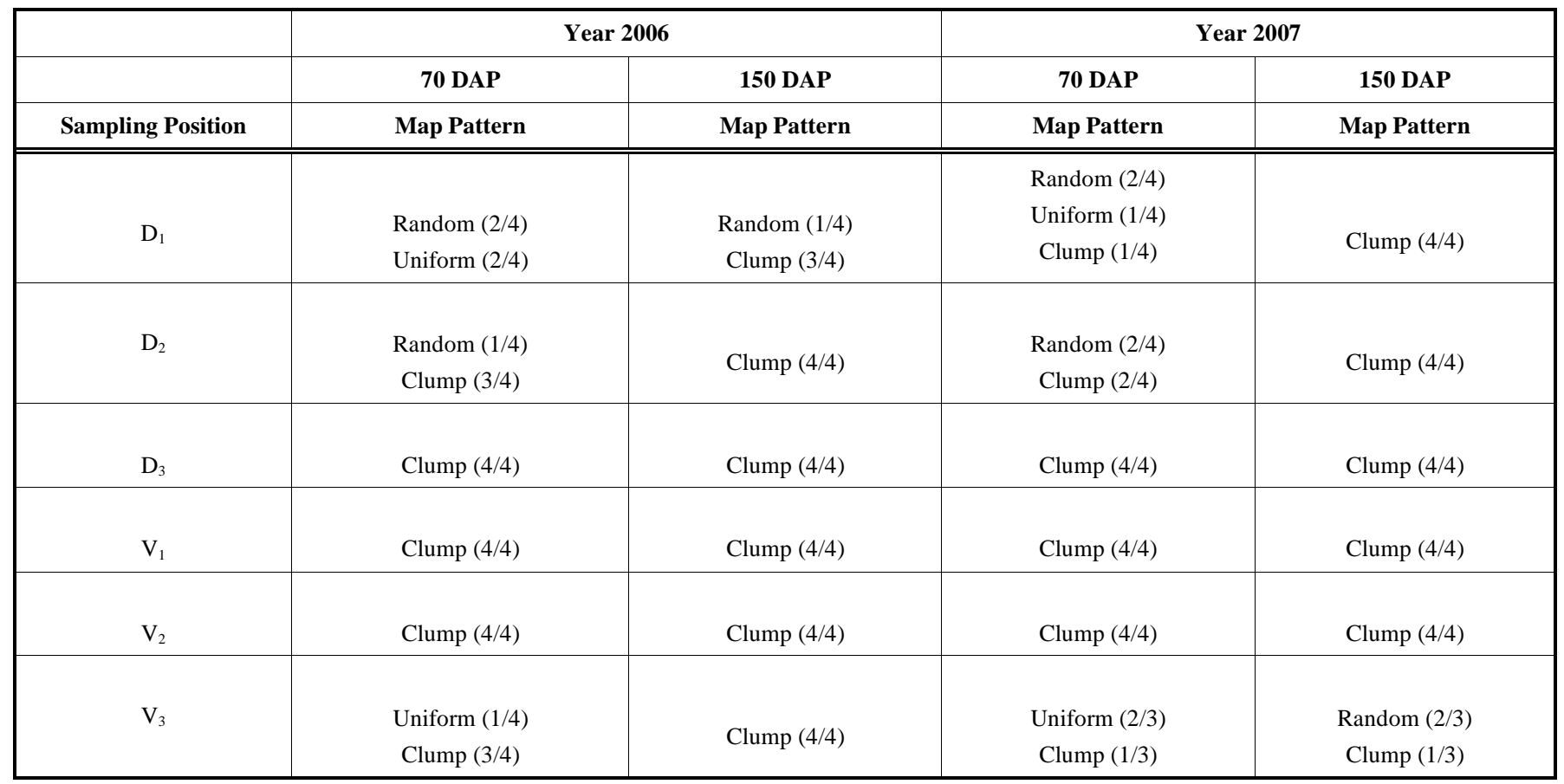

*When $\mathrm{H}_{0}$ is rejected at $\mathrm{P} \leq 0.001$, then the pattern reported is significantly non-random and the pattern is clump (R<1) or uniform $(R>1)$. $\mathrm{D}_{1}, \mathrm{D}_{2}$ and $\mathrm{D}_{3}$ correspond to $0 \mathrm{~cm}$ from the PNC to 25 and $50 \mathrm{~cm}$ depth, respectively. $\mathrm{V}_{1}, \mathrm{~V}_{2}$ and $\mathrm{V}_{3}$ correspond to $0 \mathrm{~cm}$ from the centre of the mound to 25 and $50 \mathrm{~cm}$ distance in the interrow, respectively.

in our work between the Root Length Density (RLD) and the number of roots per $\mathrm{cm}^{2}$ on the one hand, and between the Root Mass Density (RMD) and the number of roots per $\mathrm{cm}^{2}$ on the other hand, suggest that these two methods provide related yet complementary information on root distribution. Relations between the RLD and the number of roots per $\mathrm{cm}^{2}$ have been observed for many crops [19], but this is the first time that this is reported for yam. With this methodological check being positive, we can go forward to provide a description of the root system of D. alata.

\section{Description of the Root System of D. Alata}

The root system of $D$. alata observed in this study consisted of three types of roots which replaced each other over the growing season. In addition to the seminal and the adventitious roots observed by Charles-Dominique et al. [8] for a cultivar of $D$. rotundata, we also observed tubercular roots on the newly developed tuber. These tubercular roots replaced the adventitious roots 4-5 months after planting when the adventitious roots started dying off.

Root growth is influenced by genetic and environmental factors thus it is difficult to compare different species grown in different environments. The root impact numbers (RIN) measured in this study, which ranged from 0.01 to $0.17 \mathrm{~cm}^{-2}$ for yam, were less than those reported elsewhere for maize. Using the vertical profile wall technique, Tardieu [17] measured RIN two times higher, whilst Vepraskas and Hoyt [20] reported RIN ranging from 0.01 to $0.85 \mathrm{~cm}^{-2}$. Root densities (RLD and RMD) were also low in this study, even at the maximum root growth. Oikeh et al. [21] has reported 4.12 $\mathrm{cm} \mathrm{cm}^{-3}$ for maize. The values of $2.17,2.51$ and $1.20 \mathrm{mg}$ $\mathrm{cm}^{-3}$ have been reported for potatoes, maize and cassava, respectively [22, 23]. Nevertheless our data suggest that the cultivar of $D$. alata used in this study produced more roots than potatoes which have RLD of $0.27 \mathrm{~cm} \mathrm{~cm}^{-3}$ [24].

The coefficients of variation of root densities ranged from 52 to $67 \%$ which are similar to the variability observed by Lodgson and Allmaras [19]. In other respects, coefficients of variation were higher even in the surface layer $(0-15 \mathrm{~cm}$ depth) probably because of the concentration of roots [19] in the mound $\left(\mathrm{H}_{1}\right)$ and in the interrow $\left(\mathrm{H}_{3}\right)$ compared to below $15 \mathrm{~cm}$ in the mound $\left(\mathrm{H}_{2}\right)$. This suggests that D. alata is a shallow-rooting species like D. esculenta and potatoes [6, 23] with a maximum rooting depth of about $15 \mathrm{~cm}$. Generally, root growth and rooting depth are influenced by genetic factors as well as growth conditions. Soil preparation (mounding and regular weeding during crop growth which loosened the soil) and climatic conditions may have influenced root growth in yam as reported for wheat $[25,26]$. The root densities were highly correlated with root impacts number. These correlations indicated that RLD and RMD are 3.3 and 2.2 times larger than RIN, respectively. Reports in the literature comparing root density and RIN $[17,20]$ are similar to our findings but lower than 16 found by Lodgson and Allmaras [19]. These results indicated that the root distribution in D. alata was non-uniform, since root density should be about twice the RIN for uniform root distributions [27]. The root system growth dynamic observed on root maps showed a very skewed distribution, with differences between vertical and horizontal maps during the vegetative growth phase (70 DAP). However, roots were mostly distributed as clumps at the tuber bulking phase (150 DAP). Root distributions are clumped because of lateral formation, row effect and growth concentrated in existing soil pores while other 
regions of soil are unexplored [17]. The increase of the variability of root density in the interrow resulting in the increase of the coefficient of variation with distance suggests that the preferred orientation of roots for growth was horizontal as reported by Lodgson and Allmaras [19] for maize.

The average root diameter for $D$. alata found in this study was similar to that reported by Charles-Dominique et al. [8] for D. rotundata. These values are 2-3 times higher than those reported by Vos and Groenwold [23] for potatoes indicating that yams produce coarser roots.

\section{Root distribution and plant growth}

Root growth and distribution observed in this study were very variable overtime. Before tuber initiation $(0-100$ DAP), the root system consisted of adventitious roots (generally coarse) which grew in the mounds. The distance between the roots increased with the depth and the root distribution changed from uniform or random at the PNC level to a clumpier pattern deeper in the soil profile, probably to allow for a better exploration of nutrient-rich niches. From tuber initiation to tuber bulking phase (100 - 160 DAP), the root system consisted of branched adventitious roots and tubercular roots which spread out radially in the interrow as both RLD and RMD increased significantly in $\mathrm{H}_{3}$, whilst they decreased in $\mathrm{H}_{2}$. This confirms that the direction of root growth was preferentially horizontal. At this period, the roots were distributed as clump in both the mound and the interrow. Unlike Melteras et al. [6] who observed maximum root extension before tuber initiation in $D$. esculenta, our results suggest maximum root proliferation period during the tuber bulking phase. Root clumping patterns observed in this study may be attributed to root proliferation in a given volume for nutrient and water uptake or to soil physical heterogeneity as reported for maize and soybean $[16,17,19]$. During the tuber maturation phase (160 - 190 DAP), the root system started to senesce resulting in a decrease of both root mass density and average root diameter, but the root length density still increased, probably due to tubercular roots.

Rooting depth in the interrow in this study did not exceed $15 \mathrm{~cm}$ in contrast to O'Sullivan [7] who reported a rooting depth of $40 \mathrm{~cm}$ at a distance of $50 \mathrm{~cm}$ from the plant for the cultivar Paholo of $D$. alata. These differences could be explained by the use of a different cultivar, or/and cultivation technique, as in Oceania the mound is only $15 \mathrm{~cm}$ high [7] compared to $50 \mathrm{~cm}$ in West Africa. Agbede [28] showed that the tuber production of $D$. rotundata was significantly lower in untilled soils compared to the production obtained with mounding or ridging. This author interpreted the lower tuber production in the untilled soil as the result of increased impedance to root and tuber growth due to the higher soil bulk density observed in this treatment compared to the traditional mounding.

\section{Effect of Year on Root Growth}

Weather conditions may affect the growth of plant roots through changes in soil conditions (e.g. soil water content and soil temperature) [29]. In our study, the plants had longer and thinner roots in the drier year of 2006, but shorter and thicker roots in the rainier year of 2007, indicating a plasticity of the root system across varying climatic conditions. This result is in agreement with findings of Kovar et al. [30] and Qin et al. [29] on maize, and those of Pardales et al. [31] on sweet potatoes and cassava. These authors found that the RLD was higher in year and/or depth with higher soil temperature and lower water availability. In contrast to the other root growth parameters, the specific root length (SRL), defined as the ratio between root length density and root mass density, remained stable over the growing season in the two experimental years. This suggests that the SRL may be a genetic factor for this yam cultivar and it may explain the adaptation of the root system of $D$. alata to growth conditions across the years.

A year effect was observed on the root distribution pattern in the interrow during the tuber bulking phase. While roots were distributed as clumps in 2006, the distribution pattern was mostly random in 2007, suggesting that root branching or/and soil colonisation and exploitation activity were more marked in 2006 than in 2007.

\section{Fertiliser, root growth and yield}

Fertiliser application had no significant effect on root growth. Root biomass, root length and mass densities, and average root diameter were not affected by fertiliser application, whereas shoot and tuber biomass were often significantly increased by fertiliser application in both years. This indicates that the yam root system is less responsive to fertiliser as opposed to its responsiveness to soil temperature. The erratic response of yam tuber to fertiliser could not be observed here, except during the last growth phase in 2006 when shoot dry matter decreased dramatically in the fertilised plots, without a mirrored pattern in tuber dry matter. This could have been due to water stress in the last growing month in 2006 as the plots were not irrigated anymore. The water shortage observed during this growth phase caused an early senescence of plants in both fertilised and nonfertilised plots. This probably hindered the transfer of assimilates accumulated in aerial organs to the tuber in the fertilised plots. It appears therefore that the root system is not the missing link between fertiliser and tuber yield, but our results indicate that the erratic response of yam to fertiliser may be related to other stress factors, that reduce or even nullify the effect of fertiliser, and to which the plant is not able to adapt.

\section{CONCLUSIONS}

Compared to other crops D. alata showed to be, a shallow-rooting species with coarse and low density roots. The root system was composed of three root types which followed each other: the seminal roots that grew directly from the planted sett, the adventitious roots growing from the primary nodal complex and the tubercular roots growing on the newly-developed tuber. Under our study conditions, $D$. alata developed most of its roots within the mound till tuber initiation only afterwards emitted roots outside of the mound. When growing outside of the mound, roots stayed in the first $15 \mathrm{~cm}$ soil horizon. Maximal root growth was observed at 160 DAP. The specific root length was constant over the two growing seasons, suggesting that it is a genetically fixed parameter for this cultivar. The root length density was higher in 2006 under relatively dry conditions than in 2007 under relatively wet conditions. Horizontal and vertical root mapping showed that roots were mostly distributed as clumps. Root growth was not affected by fertiliser application. Our 
study revealed that tuber yield was not directly linked to the root morphology, but probably to other stress factors such as late water stress.

\section{ACKNOWLEDGEMENTS}

This project was supported by the Swiss Development and Cooperation Agency (SDC) through the Research Fellowship Partnership Program managed by North-South Center of the ETH-Zurich, which is gratefully acknowledged. Thanks are extended to Ms Tope Louise (CSRS), Ms Aka Marie-Berthe (CSRS), Dr. Tiziana Centofanti (ETH), Dr. Juan Herrera (ETH), Dr. Markus Liedgens (ETH) and Dr. Fabian Rohner (ETH) for helpful discussions during the preparation of the manuscript.

\section{REFERENCES}

[1] Diby LN, Hgaza VK, Tié TB, et al. How does soil fertility affect yam growth? Acta Agricult Scand Sec B - Soil Plant Sci 2011; In press.

[2] Frossard E, Bünemann EK, Carsky R, et al. Integrated nutrient management as a tool to combat soil degradation in sub-Saharan Africa. In: Bearth T BB, Kappel R, Krüger G, Pfister R, editor. Afrika im Wandel. Züricher, Hochschulforum Band 40, Zürich, Switzerland; 2007. p. 137-46.

[3] IITA, CIRAD. Soil fertility management for yam-based systems: A review of literature. Project Report: IITA (International Institute of Tropical Agriculture) and CIRAD (Centre de Coopération Internationale en Recherche Agronomique pour le Développement); 2003.

[4] O'Sullivan JN, Ernest J. Yam nutrition and soil fertility management in the Pacific. Brisbane: Australian Centre for International Agricultural Research; 2008.

[5] Sotomayor-Ramirez D, Gonzales-Vélez A, Roman-Paoli E. Yam (Dioscorea spp) response to fertilization in soils of semiarid southern coast of Puerto Rico. J Agric Univ P R 2003; 87 (3-4): 91-103.

[6] Melteras M, Lebot V, Asher CJ, O'Sullivan JN. Crop development and root distribution in lesser yam (Dioscorea esculenta): Implications for fertilization. Exp Agricult 2008; 44: 209-21.

[7] O'Sullivan JN. Root distribution of yam (Dioscorea alata) determined by strontium tracer. Exp Agricult 2008; 44: 223-33.

[8] Charles-Dominique T, Mangenet T, Rey H, Jourdan C, Edelin C. Architectural analysis of root system of sexually vs. vegetatively propagated yam (Dioscorea rotundata Poir.), a tuber monocot. Plant Soil 2009; 317 (1-2): 61-77.

[9] Pagès L, Pellerin S. Study of differences between vertical root maps observed in maize crop and stimulated maps obtained using a model for the three-dimensional architecture of the root system. Plant Soil 1996; 182: 329-37.

[10] Watson WT, Appel DA, Arnold MA, Kenerly CM. Spatial distribution of Malus root system in irrigated, trellised orchards. J Horticut Sci Biotech 2006; 81 (4): 745-53.

[11] Tschannen A. Controlling Post-Harvest Losses of Yam (Dioscorea spp.) by Application of Gibberelic Acid. Zurich: Swiss Feredal Institut of Technology; 2003.
[12] Walkley A, Black IA. An examination of the Degtjareff method for determining soil organic matter, and a proposed modification of the chromic acid titration method. Soil Sci 1934; 34.

[13] Bremner JM. Total nitrogen. In: Black CA, editor. Methods of soil analysis. Part 2: Madison, WI, USA: Am Soc Agron 1149-1178; 1965.

[14] Smucker AJM, Srivastava AK, McBurney SL. Quantitative separation of roots from compacted soil profiles by the hydropneumatic elutriation system. Agron J 1982; 74: 500-3.

[15] Himmelbauer ML, Loiskandl W, Kastanek F. Estimating length, average diameter and surface area of roots using two different image analyses systems. Plant Soil 2004; 260: 111-20.

[16] Pellerin S, Pagès L. Evaluation in field conditions of a threedimensional architecture model of the maize root system: Comparison of stimulated and observed horizontal root maps. Plant Soil 1996; 178: 101-12.

[17] Tardieu F. Analysis of spatial variability of maize root density: I. Effect of wheel compaction on spatial arrangement of roots. Plant Soil 1988; 107: 259-66.

[18] Clark PJ, Evans FC. Distance to nearest neighbor as a measure of spatial relationships in populations. Ecology 1954; 35: 445-53.

[19] Logsdon SD, Allmaras RR. Maize and soybean root clustering as indicated by root mapping. Plant Soil 1991; 131: 169-76.

[20] Vespraskas MJ, Hoyt GD. Comparison of the trench-profile and core methods for evaluating root distribution in tillage studies. Agron J 1988; 80: 166-72.

[21] Oikeh SO, Kling JG, Horst WJ, Chude VO, Carsky RJ. Growth and distribution of maize roots under nitrogen fertilization in plinthite soil. Field Crops Res 1999; 62: 1-13.

[22] Lal R, Mauray PR. Root growth of some tropical crops in uniform columns. Plant and Soil 1982; 68: 193-206.

[23] Vos J, Groenwold J. Root growth of potato crops on a marine-clay soil. Plant Soil 1986; 94: 17-33.

[24] Wang F-X, Kang Y, Liu S-P. Effects of drip irrigation frequency on soil wetting pattern and potato growth in north China plain. Agricult Water Manag 2006; 79: 248-64.

[25] Qiang Z, Shi J, Yulan L, Renduo Z. Root length density and water uptake distributions of winter wheat under sub-irrigation. Plant Soil 2006; 285: 45-55.

[26] Xue Q, Zhu Z, Musick JT, Stewart BA, Dusek DA. Root growth and water uptake in winter wheat under deficit irrigation. Plant Soil 2006; 257: 151-71.

[27] Melhuish FM, Lang ARG. Quantitive studies of roots in soil. I. Length and diameter in cotton roots in a clay-loam soil by analysis of surface-ground blocks of resin-impregnated soil. Soil Sci 1968; 106: 16-22.

[28] Agbede TM. Effect of tillage on soil properties and yam yield on an Alfisol in southwestern Nigeria. Soil Tillage Res 2006; 86: 1-8.

[29] Qin R, Stamp P, Richner W. Impact of tillage on maize rooting in a Cambisol and Luvisol in Switzerland. Soil Tillage Res 2006; 85: 50-61.

[30] Kovar JL, Barber SA, Kladivko EJ, Griffith DR. Characterization of soil temperature, water content, and maize root distribution in two tillage systems. Soil Tillage Res 1992; 24: 11-27.

[31] Pardales JR, Banoc MD, Yamauchi A, Lijima M, Kono Y. Root System Development of Cassava and Sweetpotato during Early Growth Stage as Affected by High Root Zone Temperature. Plant Prod Sci 1999; 2 (4): 247-51. 